of the Journal. It is, of course, not in the least surprising that Mr. King should personally prefer to adhere to the Notation which he himself devised and employs in practice, and which is therefore familiar to him, rather than to adopt any new Notation. The question is, however, one in which differences of opinion may well arise, and it will, no doubt, be eventually settled by the general body of professional opinion after independent consideration of the various Notations which may be suggested. The Journal is, perhaps, not a fitting place for a detailed discussion of the subject, and the comparative merits of the two Notations can be sufficiently appreciated by inspection of the symbols given in parallel columns in my letter on p. 209 of the current volume of the Journat. I would only add that Mr. King hardly seems entitled to claim that he has used only one symbol, as compared with six suggested by me, when the fact is that his one symbol, namely, $\mathbf{F}$, is so little distinctive that it has to be supplemented by no less than seven subsidiary symbols-in addition to the letters representing ages, which appear equally in both systems.

G. J. L.

\title{
ON THE VALUATION OF POLICIES IN GROUPS.
}

[We have received the following interesting letter from our esteemed Corresponding Member, Herr Altenburger, as to the paper by Mr. F. Bell, published in the present volume of the Journal.—ED. J.I.A.]

To the Editor of the Journal of the Institute of Actuaries.

Dear SIr,- I have read with very great interest the discussion which followed the reading of Mr. Fred. Bell's paper relative to the calculation of reserves in groups; and as my name, and the letters I had the honour to address in this matter to the Journal (xxxiv, p. 150 ; xxxv, p. 332) have been frequently mentioned, I think it necessary to explain my standpoint concerning the valuation of policies.

It is true, that the method dealt with in my letters is almost generally used in Germany and in Austria (not here in Hungary), but this fact is due to the circumstance that Actuaries in these countries have not liberty to make their valuations according to any principles which commend themselves to them, their companies being under the control of governments, which do not permit a free choice of the methods and bases of valuations. In Austria, for example, it is not permissible to use the method invented forty years ago by the late Dr. Zillmer (see J.I.A., xv., p. 420), which is almost identical with the method explained by Dr. Sprague at the Brussels Congress (Transactions of the First International Congress of Actuaries, p. 186, et seq.), but it is compulsory to make the valuation on a net premium basis, although the rate of interest may be taken as 4 per-cent, even where the funds do not yield a higher rate.

The position of Actuaries is then:-Valuations have to be made annually, the basis of this work is invariable for a long term; is 
it not natural that Managers and Actuaries search for means whereby their work can be simplified? These are the reasons of the origination and the wider adoption of the method in question.

Fortunately the outlook seems more promising. Governments and Directors begin to give more regard to the principles of actuarial science ; and I think that in five or, perhaps, ten years, there will be no obstacle to the adoption of the ingenious method of Mr. Lidstone also in the countries referred to.

I am, Dear Sir, with the expression of my greatest respect, Truly yours,

JULIUS ALTENBURGER.

V., Mária Valéria-ut., 15a., Budapest, Hungary.

14 February 1905. 